\title{
REFLEXÕES SOBRE A CONSTITUIÇÃO DE UMA HISTÓRIA ORIENTADA PARA A FORMAÇÃO INICIAL DE PROFESSORES DE MATEMÁTICA
}

\section{Reflections on the building of a history of mathematics for pre-service teacher education}

\author{
Márcia Cristina de Costa Trindade Cyrino ${ }^{1}$ \\ Júlio Faria Corrêa ${ }^{2}$
}

\begin{abstract}
Resumo: Relatam-se algumas reflexões sobre a participação da história na formação inicial de professores de Matemática, produto de uma investigação que teve como objetivo constituir uma história sobre alguns métodos de determinação de áreas, particularmente de alguns trabalhos sobre a quadratura de figuras planas, orientada para a educação matemática de futuros professores de Matemática. Na constituição dessa história utilizamos a perspectiva de uma História Pedagogicamente Vetorizada proposta por Miguel e Miorim. Neste texto, apresentamos questões problematizadoras e reflexões sobre a cultura matemática na qual foram construídos esses métodos, que podem evidenciar múltiplas dimensões da Matemática, tirando-a de seu suposto isolamento das demais práticas sociais que participam da constituição dessa cultura matemática.
\end{abstract}

Palavras-chave: História na educação matemática. Formação inicial de professores de matemática.

\begin{abstract}
We present in this paper some reflections on the participation of history in the pre-service Mathematics Teacher Education. These reflections are product of an investigation which goal was to constitute a history on some methods of area determination, particulary of some works about plane figures areas, guided for pre-service Mathematics Teacher Education. In the building of this history we used the perspective of The Guided Pedagogical History proposed by Miguel and Miorim. In this text we present some problematizations and reflexions about the mathematical culture, in which those methods were built, that can give evidence to the multiple dimensions of the Mathematics, removing it from its supposed isolation of other social practices that participate of the formation of this mathematical culture.
\end{abstract}

Keywords: History in the mathematics education. Pre-service mathematics teachers.

\footnotetext{
${ }^{1}$ Matemática. Doutora em Educação. Docente, Departamento de Matemática, Universidade Estadual de Londrina (UEL) Londrina, PR. Fundação Araucária. CNPq.<marciacyrino@uel.br>

${ }^{2}$ Matemático. Mestrado em Ensino de Ciências e Educação Matemática. Docente, Colégio Brasileiro de Estudos Sistêmicos (CBES). Curitiba, PR. Fundação Araucária. CNPq. <juliofc13@gmail.com>

${ }^{1}$ Rua Professor Samuel Moura, n. 328, apto. 1604

Londrina, PR

$86.061-060$ 


\section{Introdução}

Estudos sobre aspectos envolvidos nas relações entre a história e a educação matemática, em todos os níveis educacionais, têm mobilizado muitos educadores matemáticos nos últimos anos. O International Study Group on the Relations Between the History and Pedagogy of Mathematics do ICMI Study, the International Commission on Mathematics Instruction, tem reunido uma diversidade de trabalhos na busca de compreender o papel da história da matemática no ensino da matemática. Dentre esses estudos, temos analisado aqueles que discutem a participação da história da matemática na formação inicial professores de Matemática.

Nos últimos anos, nosso grupo de estudo e pesquisa tem investigado possíveis modos de relacionar o desenvolvimento histórico de um determinado conhecimento matemático e a constituição ou apropriação deste por futuros professores de Matemática (CYRINO e CORRÊA, 2007). A questão básica assumida refere-se ao modo de se conceber a relação entre a cultura matemática (cultura entendida como o conjunto de formas simbólicas ${ }^{3}$ até hoje produzidas) e as formas de apropriação dessa cultura no presente (MIGUEL e MIORIM, 2004), ou seja, os vínculos que podem ser promovidos entre filogênese (a produção sócio-histórica do conhecimento) e a psicogênese (produção ou apropriação deste conhecimento no presente).

Existem várias maneiras de se conceber a relação entre filogênese e psicogênese. Radford, Boeiro e Vasco (2000) discutem as perspectivas de: Obstáculo Epistemológico, Sociocultural e dos "Jogos de Vozes e Ecos". Além destas, Miguel e Miorim (2004) descrevem outras quatro, nomeadamente: Evolucionista Linear; Estrutural-Construtivista Operatória; Evolutiva Descontínua e a perspectiva proposta por eles de uma História Pedagogicamente Vetorizada, que defende uma concepção orgânica da participação da história na produção do saber docente por meio da problematização.

[...] a história - desde que devidamente constituída com fins explicitamente pedagógicos e organicamente articulada com as demais variáveis que intervêm no processo de ensino-aprendizagem escolar da matemática - pode e deve se constituir um ponto de referência tanto para a problematização pedagógica quanto para a transformação qualitativa da cultura escolar e da educação escolar e, mais particularmente, da cultura matemática que circula e da educação matemática que se promove e se realiza no interior da instituição escolar. (MIGUEL e MIORIM, 2004, p. 151)

No presente artigo apresentamos e discutimos parte de uma investigação que teve como objetivo constituir uma história pedagogicamente vetorizada para a formação inicial de professores de Matemática sobre métodos de quadratura de figuras planas, a partir de episódios do antigo Egito, da Babilônia, e dos trabalhos de quadratura de Hipócrates, Arquimedes e Fermat. Mais especificamente, centramos nossa discussão sobre alguns aspectos que fundamen-

\footnotetext{
${ }^{3}$ Segundo Thompson (2002), são formas simbólicas: expressões linguísticas, gestos, ações, obras de arte etc. Ele ainda destaca cinco características das formas simbólicas: intencionais, convencionais, estruturais, referenciais e contextuais.
} 
Reflexões sobre a constituição de uma história ...

tam e caracterizam uma História Pedagogicamente Vetorizada (MIGUEL e MIORIM, 2004) e sobre a participação desta na formação de professores de Matemática. Apresentamos alguns questionamentos e reflexões geradas a partir da análise dos contextos dos episódios em que foram construídos os métodos de determinação de áreas de figuras planas citados anteriormente, que podem ser orientados à formação inicial de professores de Matemática de modo a explicitar a influência das práticas sociais ${ }^{4}$ e das relações de poder na constituição destes métodos.

\section{História Pedagogicamente Vetorizada e a formação de professores de Matemática}

A forma de participação da história, defendida por Miguel e Miorim (2004), não é a de uma história que deva ser discutida em uma única disciplina no curso de Licenciatura em Matemática, mas que seja trabalhada de forma orgânica, articulada por diferentes disciplinas e atividades constituintes da formação inicial de professores de Matemática. O adjetivo orgânica busca dizer que a história não é algo a mais para ser colocado em meio ao que já é trabalhado, mas que faça parte da e seja indispensável à formação de futuros professores.

A idéia não é, somente, acrescentar histórias sobre a matemática ou matemáticos ao que já vem sendo trabalhado, mas que a história tenha o papel de problematizar este trabalho, sem desmerecê-lo. Não se trata de abolir a abordagem axiomática, mas questioná-la no sentido de saber quando ela é necessária ou não, e apontar outras possibilidades de trabalho. Em uma aula de cálculo, por exemplo, a história poderia permear o programa de modo que o futuro professor possa questionar e redirecionar a ordem dos temas abordados, os problemas a serem discutidos, os métodos a serem utilizados, os objetivos a serem atingidos.

Miguel e Miorim (2004) defendem que, nos cursos de Licenciatura em Matemática, seja fomentada interconexão entre história e educação matemática nos diferentes campos de investigação - quais sejam: História da Matemática, História da Educação Matemática e História na Educação Matemática - por meio da problematização da educação matemática escolar.

A participação orgânica da história na formação inicial de professores de Matemática pode contribuir para problematizar o conhecimento matemático e explicitar outras dimensões deste conhecimento (como política, ética, estética, epistemológica etc.) e não somente a dimensão lógico-axiomática. Esta concepção nos dá uma possibilidade de buscar, em outras histórias (e não somente na História da Matemática), argumentos que possam auxiliar a problematização do conhecimento matemático, ou, mais amplamente, da cultura matemática escolar.

A ideia de problematização é fundamental nesta maneira de se conceber a participação da História na educação matemática de futuros professores, e se caracteriza por ser multidimensional, interativo-dialógica e investigativa.

${ }^{4}$ Miguel (2003) e Miguel e Miorim (2004). 
- Multidimensional por incidir sobre várias dimensões da cultura matemática e da Educação Matemática escolar, tais como: a dimensão epistemológica, lógica, histórica, ética, política etc.

. Interativo-dialógica por buscar a interação e o diálogo entre os diversos atores que influenciam na constituição da cultura matemática e da educação matemática escolar (matemáticos, professores de Matemática, diretores de escolas, pais, alunos, políticos, dentre outros) ${ }^{5}$.

. Investigativa por iniciar o futuro professor nos diferentes campos de investigação da História da Matemática (MIGUEL e MIORIM, 2004).

De acordo com estes autores, a problematização procura exercer quatro papéis. $\mathrm{O}$ papel interdisciplinar, que possibilita tirar a Matemática do seu confinamento e tomar seu lugar na formação crítica do cidadão; o papel didático-metodológico, por ser um meio crítico e humano de apropriação e (re)significação do saber e, ainda, possibilitar, ao futuro professor, uma ampliação e uma flexibilização das possibilidades a serem seguidas em sua prática em sala de aula; o papel psicológico motivacional, visto que pode propiciar um ambiente que estimula o envolvimento e a participação ativa do estudante; e o papel político-crítico, pois tende a propiciar discussões sobre as relações de poder que influenciam e são influenciadas pelo saber matemático em diferentes momentos e lugares.

São discutidas três características da História Pedagogicamente Vetorizada. A primeira é que ela é uma história institucional da cultura matemática, ou seja, uma história que deveria se constituir a partir de problemas e questões que emergem ou se relacionam com os diversos momentos ou lugares em que a Matemática está envolvida (escola, pesquisas em diversas áreas do conhecimento, mídia, religião, política etc.); deve buscar explicitar as complexas relações entre a Matemática e outras práticas sociais. A segunda é a noção de históriaproblema, isto é, uma história que busca questionar, colocar problemas que se manifestam tanto nas práticas do professor de Matemática quanto do pesquisador em Educação Matemática. O terceiro aspecto se refere ao modo de se encarar a historiografia. Aqui ela é concebida como uma fonte de diálogo e não de respostas ou procedimentos a serem repetidos no presente. A história não é um objeto para ser usado, mas um campo de diálogo, uma fonte de problematizações. Este tipo de história não adere ao princípio recapitulacionista, pois não vê, na história, uma fonte de problemas pelos quais os estudantes devem passar para constituírem o conhecimento, mas como uma fonte de problematizações que podem auxiliar o estudante ou, em nosso caso, o futuro professor de Matemática na constituição de seu conhecimento, não só matemático, mas também pedagógico.

Miguel e Miorim (2004) destacam ainda duas noções fundamentais à constituição de uma história pedagogicamente vetorizada: prática social e poder. Para eles, práticas sociais são

[...] um conjunto de atividades ou ações físico-afetivo-intelectuais que se caracterizam por ser: (1) conscientemente orientadas para certas finalidades; (2) espácio-temporalmente configuradas; (3) realizadas sobre o mun-

\footnotetext{
${ }^{5}$ Em nosso trabalho, este papel foi limitado, pois a interação e o diálogo ocorreram somente entre pesquisador e textos históricos. O que não é pouco, pois tanto pesquisador quanto textos históricos estão imersos em diferentes práticas sociais.
} 
Reflexões sobre a constituição de uma história ...

do natural e/ou cultural por grupos sociais cujos membros estabelecem entre si relações interpessoais que se caracterizam por serem relações institucionais de trabalho organizado; (4) produtoras de conhecimentos saberes, tecnologias, artefatos culturais ou em uma palavra, de um conjunto de formas simbólicas. (MIGUEL e MIORIM, 2004, p. 165)

A noção de poder assumida por Miguel e Miorim (2004, p. 164) é a referida por Foucault, ou seja, como relações de poder, e não como o poder, "não existe o poder fixamente e inteiramente centrado em um lugar ou pessoa, e daí o estatuto ontológico da noção sociológica de poder é o de uma relação", e as relações de poder são um conjunto que contém quatros conjuntos:

[...] (1) o conjunto de correlações de forças entre pessoas e/ou grupos sociais, que os ordena assimetricamente segundo o critério de dominação ou subordinação; (2) o conjunto de transformações dessas correlações de forças no período de tempo considerado; (3) o conjunto de todos os modos de organização, por aproximação ou afastamento, que tais correlações de forças assumem nesse jogo sutil de transformações dessas correlações de força; (4) o conjunto de estratégias constitutivas de tais correlações de forças. (MIGUEL e MIORIM, 2004, p. 164)

Esses autores ressaltam ainda que, para Foucault, as relações de poder são práticas sociais, ou seja, as relações de poder são orientadas para certas finalidades, são configuradas espacial e temporalmente, realizadas sobre o mundo natural ou cultural por grupos sociais, e têm como uma característica a produção de conhecimentos. Segundo eles, Foucault apresenta uma maneira nova de encarar a relação entre teoria e prática, que é uma relação de identidade, ou seja, uma teoria é uma prática social.

Contar uma história pedagogicamente vetorizada é contar uma história a partir de diferentes práticas sociais que participaram da constituição e transformação do problema e que seja: mais do que uma discussão estritamente técnica do problema (diferenciando-se da história do historiador da matemática que dá ênfase aos aspectos técnicos); mais do que uma apresentação das diferentes formas do problema por diferentes grupos sociais ao longo do tempo; mais do que uma história das necessidades de outros campos do conhecimento e de outras práticas sociais que fizeram o problema surgir e se desenvolver; uma história que contemple as razões que levaram diversos grupos sociais a valorizarem o problema em questão; uma história das diversas mudanças sofridas pelo problema no interior das diversas práticas sociais de diferentes épocas e contextos, e uma história que discuta as relações de poder relacionadas ao problema (MIGUEL e MIORIM, 2004).

\section{Encaminhamento metodológico}

A história pedagogicamente vetorizada é uma história orientada por objetivos pedagógicos, por questões colocadas por professores de Matemática, ou investigadores em Educa- 
ção Matemática. É uma história constituída sob o ponto de vista do educador matemático, e não do historiador da matemática ou do matemático. Entretanto ela não é uma história suavizada, distorcida, ou uma adaptação de histórias já constituídas para a escola. A perspectiva que apresentamos coloca uma discussão sobre o como fazer história, sobre o papel do historiador. Não está sendo proposto o uso de uma história, mas a constituição, por futuros professores, de uma história orientada por questões pedagógicas.

$\mathrm{Na}$ constituição de uma história pedagogicamente vetorizada sobre a quadratura de figuras planas, estudamos a cultura matemática presente em episódios que envolveram: os processos de determinação de áreas no antigo Egito, na Babilônia, e nos trabalhos de quadratura de lúnulas proposto por Hipócrates de Quios, o método de quadratura de Arquimedes e o método de quadratura de hipérboles proposto por Fermat, na busca de elaborar e responder algumas questões problematizadoras.

Por meio desse estudo, buscamos compreender o que os matemáticos fizeram em seu tempo, e evidenciar episódios da cultura matemática que oportunizassem aos estudantes futuros professores - conhecer e dialogar com diferentes práticas sociais do passado. Não como uma forma de repetir esta cultura, ou de dizer o que ela não conseguiu fazer, mas de buscar diferentes formas de se encarar problemas na tentativa de compreender os próprios problemas, assumindo que o papel do historiador é o de compreender, e não julgar (BLOCH, 2001).

Apresentamos, a seguir, algumas questões problematizadoras, elaboradas com base nesse estudo sobre a cultura matemática - na qual foram construídos os métodos de determinação de áreas de figuras planas investigados - que podem ser orientadas para a formação inicial de professores de Matemática, de modo a explicitar a influência das práticas sociais na constituição destes métodos. Bem como algumas reflexões desencadeadas na tentativa de responder algumas destas questões.

Acreditamos que essas questões podem oportunizar um diálogo entre textos, pesquisadores e futuros professores, visto que a história "se constitui num processo contínuo de interação entre o historiador e seus fatos, um diálogo interminável entre passado e presente" (CARR, 2002, p. 65).

\section{Questões problematizadoras e reflexões sobre episódios de determinação de áreas de figuras planas}

Buscamos, nos episódios investigados, uma história que explicitasse as práticas sociais e relações de poder que influenciaram a contrução dos métodos de determinação de áreas de figuras planas (quadraturas). As questões iniciais orientadoras deste processo foram:

- Que práticas sociais influenciaram os métodos de quadratura presentes nos episódios estudados?

- Como essas práticas sociais influenciaram estes métodos?

- Existiam relações de poder que condicionavam o desenvolvimento destes métodos?

- Que questões sociais, culturais, econômicas e políticas influenciaram estes métodos?

- Que razões levaram à valorização dos episódios que estudamos? 
$\mathrm{Na}$ busca de responder a estas questões, foi desencadeado um processo de reflexão que promoveu o surgimento de outras questões. Estas questões e reflexões foram organizadas e associadas em relação: à concepção da natureza dos objetos matemáticos, às idéias de rigor e axiomatização, de beleza matemática, ao estabelecimento de relações da Matemática com outros campos do saber, aos aspectos éticos e políticos, e aos de motivos que levaram as pessoas a fazerem matemática (MIGUEL e BRITO, 1996).

\section{Concepção da natureza dos objetos matemáticos}

Enquanto os egípcios e babilônios desenvolveram uma matemática voltada para soluções de problemas práticos, tais como problemas de medidas de terreno, contagem de grãos, determinação de volumes, Arquimedes e Hipócrates desenvolveram outro tipo de matemática, que se encontra na etapa das 'magnitudes constantes'. Mudanças importantes ocorrem nesse período: a matemática começa a se desenvolver teoricamente, cria-se o método dedutivo e a ideia de uma matemática axiomática.

Por que no antigo Egito existia uma matemática prático-empírica? Esse fato tem relação com a política, com a religião, com as cheias do Nilo? Por que a natureza da matemática se modifica na Grécia antiga, passando a tratar de questões abstratas? O que pode ter provocado esta mudança no modo de conceber a natureza dos objetos matemáticos?

Os gregos desenvolveram muito a abstração e a generalização, não por conta de problemas estritamente lógicos, mas por uma grande influência do logos e do agon, ou seja, o culto à razão e à excelência individual (JAGUARIBE, 2001). O aumento do número de escravos, a difusão da leitura e da escrita, o desenvolvimento do comércio, a falta de uma religião concentradora, podem ter provocado o surgimento de um homem que desprezava trabalhos braçais (relegados aos escravos) e que tinha tempo e liberdade religiosa para questionar a razão de as coisas serem como são, enaltecendo a contemplação (atribuída aos intelectuais).

\section{Rigor e axiomatização}

O rigor e a axiomatização foram fortemente cultivados pelos gregos. Prova disso são os elementos de Euclides que, durante séculos, foram encarados, por muitos, como os padrões de rigor e axiomatização na Matemática. Tanto Hipócrates quanto Arquimedes utilizaram estes padrões. Arquimedes, em particular, estabeleceu uma forma de demonstração (redução ao absurdo e método de exaustão) que foi seguida, durante muitos anos, por vários matemáticos. Mesmo que tivesse feito sua descoberta de maneira distinta, Arquimedes sempre apresentava seus resultados por meio destes padrões (o que parece ser perpetuado pelos matemáticos até hoje). Struik (1997) comenta esta predominância do método de demonstração (método de exaustão) em relação ao método de descobertas (método atomista).

É significativo que em quase todos os textos clássicos fosse utilizado o primeiro método. Esta questão pode-se relacionar com o facto de a matemática se ter tornado um passatempo da classe ociosa, que se apoiava na 
escravatura, indiferente às invenções e interessada na contemplação. Pode ser também o reflexo da vitória do idealismo platônico em relação ao materialismo de Demócrito no domínio da filosofia. (STRUIK, 1997, p. 88)

Uma pergunta que pode ser feita aos futuros professores, relacionada a essa axiomatização euclidiana, é: ela tem alguma influência sobre a matemática escolar atual? Em caso positivo, como isso pode ser percebido?

A atitude de Arquimedes em relação às suas publicações pode ser atribuida a uma prática social da época - a contemplação em oposição à invenção - ou pode ser devida a uma relação de poder, uma correlação de forças - a vitória do idealismo em relação ao materialismo, pois tinha um modo de descoberta que era desvalorizado por esse grupo. Estas correlações se modificaram com o tempo para alguns, mas não para outros, isto é, as relações de poder não são algo espacial e temporalmente bem definido e imutável, elas podem se modificar em um mesmo tempo ou espaço.

Simon Stevin e Luca Valério foram os primeiros a modificar radicalmente, no século XVI, este método de demonstração. Esta mudança ocorreu porque eles se preocuparam mais com os resultados que poderiam obter do que com a realização de uma prova que seguisse o rigor arquimediano. Stevin era engenheiro e estudava centros de gravidade, possivelmente interessado em algo prático, talvez em auxiliar seu rei em alguma guerra. Para esses matemáticos, o rigor era outro.

Fermat encontra-se no período das magnitudes variáveis, entretanto a quadratura de hipérboles deve ser vista com cuidado. Não conseguimos relacionar este trabalho de Fermat com os estudos em relação ao movimento dos corpos, que começaram a ocorrer nesta época. Entretanto, uma mudança que pode ser apontada é que ele parte de uma relação entre assíntotas, para determinar a área de uma hipérbole, quer dizer, ele define a hipérbole a partir de um referencial (as assíntotas), diferentemente dos gregos. Sua notação era distinta e foi influenciada por Viète.

O trabalho de Fermat que estudamos exemplifica o fato de que uma prática social pode possuir valores diferentes, em uma mesma época, para diferentes grupos sociais. Este matemático utilizava um método grego de demonstração e ridicularizava aqueles que não o utilizavam. Todavia ele pertencia a uma época em que alguns estudiosos começavam a deixar de lado o método grego em prol da possibilidade de novos desenvolvimentos e do tratamento de novos problemas (BARON, 1985).

A discussão de Arquimedes sobre a quadratura do círculo pode ser uma explicação da fórmula da área do círculo, que, em geral, é dada, e não questionada nos diferentes níveis de ensino. A comparação de figuras feita por Arquimedes é uma forma de mostrar de onde surgiu essa fórmula, bem como a fórmula das hipérboles que pode ser discutida a partir do trabalho de Fermat.

\section{Beleza Matemática}

A questão da beleza matemática precisa ser colocada nos cursos de formação de professores. Muitos alunos saem dos cursos de Matemática achando que a matemática é feita 
Reflexões sobre a constituição de uma história ...

apenas por demonstrações, negligenciando os aspectos da criação em matemática. Poderíamos questionar a razão de Arquimedes ter ocultado como ele determinou a área do círculo, que só pôde ser descoberto ao encontrarem um tratado intitulado "O Método", no qual ele explica seu método de descoberta (BARON, 1985). Ou ainda, discutir a questão de Fermat criticar aqueles que não seguiam o padrão grego de rigor.

Por que em matemática há ênfase nos resultados e em suas demonstrações, e não no processo de criação? Refletir sobre o ato de criação pode colaborar para que o futuro professor entenda a dimensão estética da matemática e desenvolva a imaginação necessária para o processo de criação.

\section{Relação da Matemática com outros campos do saber}

Na etapa da matemática prático-empírica, não é difícil de encontrar relação da Matemática com outros campos do saber, já que a Matemática foi desenvolvida para solucionar problemas de ordem prática. O método de cálculo de área era uma maneira de medir a terra para fins de divisão entre pessoas, pagamento de impostos etc.

Essa relação se torna mais complexa no estudo histórico do método da quadratura na matemática grega. Entretanto o que chama atenção é que o modo de organizar o saber matemático dos gregos não era alheio a sua própria cultura.

A Matemática era utilizada como instrumento de poder na degradação dos trabalhos braçais, pois era uma matemática desligada das necessidades ordinárias dos cidadãos.

Com Stevin e Luca Valério, ocorre uma mudança nos modos de fazer matemática, que passam a ser influenciados pela engenharia, por exemplo. Fermat retorna à organização grega, apesar de ter mantido correspondência com diversos matemáticos, de ter desenvolvido a teoria das probabilidades junto com Pascal, e discutido a questão de obtenção de máximos e mínimos de curvas.

\section{Aspectos éticos e políticos}

Quando falamos em Arquimedes, surgem questões relativas aos aspectos ético e político. $\mathrm{O}$ fato de Arquimedes ser filho de um astrônomo e protegido de um rei influenciou em sua história? Primeiro, porque ele era conselheiro de um rei e seu engenheiro de guerra. Segundo, porque os trabalhos de Arquimedes influenciaram o fazer matemático durante muitos anos após a sua morte, muitos matemáticos discutiram e criticaram sua obra (BARON, 1985).

Arquimedes teve condições sociais, culturais e econômicas para desenvolver sua matemática. Teve um bom ensino (estudou com um dos discípulos de Euclides em Alexandria), foi filho de astrônomo, pertenceu a uma classe favorecida e foi sustentado por um rei. Enfim, várias relações de poder permitiram que Arquimedes entrasse para a história, não só da matemática.

A situação com Fermat era um pouco distinta, pois na quadratura de hipérboles, ele retomou o rigor grego, que já estava sendo deixado de lado. Sua posição era interessante, um jurista que criticava aqueles que não seguiam as regras de beleza na Matemática, que ele julgava corretas. Por que Fermat era tão atípico em seu tempo? 
Por que pouco se fala dos trabalhos de Stevin e Valério? A mudança na concepção da natureza dos objetos matemáticos ocorrida no período das magnitudes variáveis é isenta de influências sociais?

\section{Motivos que levam as pessoas a fazerem matemática}

Há necessidade de discutirmos sobre os motivos que levam as pessoas a fazerem matemática, não que estes motivos devam ser exclusivamente teóricos, afinal Fermat é um exemplo de alguém que pode ter desenvolvido matemática por curiosidade intelectual. Ele não fez a generalização da quadratura de hipérboles para solucionar algum problema da física, da astronomia, ou mesmo da matemática. Ele o fez por prazer de estudar matemática.

Fermat permite colocar em dúvida a afirmação de que, para se fazer matemática, basta querer, afinal apesar de utilizar boa parte de seu tempo em seu trabalho como jurista, ele só pôde se dedicar à matemática por ter um sustento e uma formação que lhe permitisse tal feito. Precisamos ter o cuidado, porém, de não veicular a ideia de que somente os superdotados, os gênios são capazes de fazer matemática.

O estudo da matemática, normalmente, está ligado aos que possuem condições sociais e econômicas privilegiadas?

\section{Considerações finais}

A constituição de uma história orientada para a formação inicial de professores de Matemática não é uma tarefa simples. Primeiro, porque exige que nos apropriemos de um modo completamente particular de conceber a participação da história na educação matemática. Modo este que exige mais do que uma busca de fatos históricos sobre a vida de matemáticos e seus trabalhos, exige um novo modo de conceber e questionar estes fatos, o papel do historiador, e de pensar em possibilidades de estabelecer um diálogo não só com a História da Matemática, mas com a História da Educação Matemática, a História da Arte, a História da Ciência e de todas as histórias que possam auxiliar na educação matemática de futuros professores. Segundo, porque, tendo nos apropriado dessa forma de investigar a história, o estudo exige que nosso olhar se direcione a aspectos da história que não são tradicionalmente trabalhados.

Acreditamos que uma história dessa natureza, que contemple esse tipo de questões, pode modificar a maneira como o licenciando vê a si mesmo e a cultura matemática, mostrando como ele próprio e a cultura matemática são historicamente condicionados, influenciados por várias outras práticas sociais.

Nossa intenção não foi a de elaborar uma proposta a ser aplicada na formação inicial de professores, mas dialogar com a história, questioná-la, problematizá-la, pois é possível que, em outros momentos, outras questões e reflexões possam ser elaboradas com base nos episódios escolhidos.

Ficaram em aberto dúvidas relativas a essa história, quais sejam: será que é possível a constituição de uma história pedagogicamente vetorizada com qualquer que seja o episódio da cultura matemática? Será que é pedagogicamente interessante a constituição de tal história 
Reflexões sobre a constituição de uma história ...

com qualquer episódio? Qual trabalho matemático pode ser interessante para mostrar os processos criativos da matemática? Qual episódio pode ser interessante para ser investigado na formação de professores? Existem fontes históricas que podem nos auxiliar nesse tipo de investigação?

Por exemplo, observamos que em Katz (1998) as ideias utilizadas por Fermat são todas "traduzidas" em termos atuais. Todo o trabalho com proporções é feito para mostrar que, de uma proporção continuada entre os segmentos, podemos chegar a outra proporção continuada (do que Fermat intitula paralelogramos), que é substituída na explicação de Katz por soma de séries. As referências ao trabalho de Arquimedes são excluídas, ficando apenas a ideia de que, quando a razão das abscissas é suficientemente próxima de 1, temos a área desejada. Queremos chamar a atenção para o fato de que as justificações de Fermat são diferentes daquelas apresentadas por Katz. Fermat não utilizou soma de séries. É interessante a discussão dessas diferenças? As justificativas de Fermat para suas afirmações podem ser transformadas para a maneira como Katz as encara ou são coisas diferentes?

O importante é que, nas escolhas (episódios, conteúdos, ou outro critério), sejam privilegiados aspectos da história da matemática que permitam explicitar a evolução e o desenvolvimento da matemática, tanto por meio de objetos epistêmicos ou técnicas ${ }^{6}$; que estes aspectos possam ser direcionados para fins pedagógicos, e que fomentem reflexões e o questionamento sobre a cultura matemática nos quais estão inseridos. Devemos cuidar para que estas escolhas não se constituam em uma barreira, tanto do ponto de vista da matemática quanto do ponto de vista da história, e que privilegiem os aspectos de uma história multidimensional, interativo-dialógica e investigativa, de modo natural.

Apesar de, neste trabalho, não termos dialogado com o campo da História da Educação Matemática, ressaltamos a importância, nos cursos de formação inicial de professores de Matemática, deste diálogo como subisídio para problematização da cultura matemática escolar.

A participação da história na educação matemática, que defendemos, tem como pressuposto um diálogo com a história na busca de abalar a visão extremamente difundida de uma matemática absoluta, obsoleta, e de situar essa matemática como uma prática social influenciada por diversas outras práticas, de modo que os futuros professores possam se conscientizar da alienação causada pela visão de uma matemática sem história e de seres humanos sem história, assumindo a responsabilidade que lhes cabe de auxiliar na mudança do atual quadro educacional.

Temos um grande desafio pela frente, que é o de desenvolver pesquisas empíricas no campo da história na educação matemática (JANKVIST, 2009) que busquem responder ao porquê e ao como ela pode participar da cultura escolar. Estas pesquisas podem evidenciar, estender ou modificar as hipóteses e pretensões discutidas neste artigo sobre a participação da história na educação matemática.

${ }^{6}$ Os conceitos de objetos epistêmicos e técnicas foram introduzidos por Rheinberger (1997) e modificados por Epple (2000). 
Cyrino, M. C. C. T.; Corrêa, J. F.

\section{Referências}

BARON, M. E. Curso de História da Matemática: origem e desenvolvimento do Cálculo. Brasília: UnB, 1985. v. 1-4.

BLOCH, M. Apologia da História: ou o ofício do historiador. Rio de Janeiro: Jorge Zahar, 2001.

CARR, E. H. O que é história? 8. ed. Rio de Janeiro: Paz e Terra, 2002.

CYRINO, M. C. C. T.; CORRÊA, J. F. A história da Matemática na educação matemática de futuros professores: o problema das quadraturas. Boletim GEPEM (USU), Rio de Janeiro, n. 51, p. 45-61, 2007.

EPPLE, M. Genisis, ideen, institutionen, mathmatische Werkstätten: formen der Mathematikgeschichte - ein metahistorischer essay. Mathematische Semesterberichte, Heidelberg, v. 47, n. 2, p. 131-63, 2000.

JAGUARIBE, H. Um estudo crítico da história. 2. ed. São Paulo: Paz e Terra, 2001.

JANKVIST, U. T. On empirical research in the field of using history in mathematics education. RELIME, México, v. 12, n. 1, p. 67-101, 2009.

KATZ, V. J. A history of Mathematics: an introduction. 2. ed. Longman: Addison Wesley, 1998.

MIGUEL, A. Formas de ver e conceber o campo de interações entre filosofia e educação matemática. In: BICUDO, M. A. V. (Org.). Filosofia da educação matemática: concepções \& movimento. Brasília: Plano Editora, 2003. p. 25-44.

MIGUEL, A.; BRITO, A. J. A história da Matemática na formação do professor de Matemática. Caderno Cedes, Campinas, v. 16, n. 40, p. 47-61, 1996.

MIGUEL, A.; MIORIM, M. A. História na educação matemática: propostas e desafios. Belo Horizonte: Autêntica, 2004.

RADFORD, L.; BOEIRO, P.; VASCO, C. Epistemological assumptions about student understanding. In: FAUVEL, J.; MAANEN, J. V. (Orgs.). History in mathematics education: the ICMI study. Dordrecht: Kluwer, 2000. p. 162-7.

RHEINBERGER, H.-J. Toward a history of epistemic things: synthesizing proteins in the test tube. Stanford: Stanford University Press, 1997.

STRUIK, D. J. História concisa das matemáticas. 3. ed. Lisboa: Gradiva, 1997.

THOMPSON, J. B. Ideologia e cultura moderna: teoria social crítica na era dos meios de comunicação de massa. 6. ed. Petrópolis: Vozes, 2002.

Artigo recebido em janeiro de 2009 e aceito em junho de 2009. 